\title{
NOx Sensor for Direct Injection Emission Control
}

\section{FINAL REPORT}

Reporting Period Start Date: $\quad$ 10/01/2001

Reporting Period End Date: 09/30/2005

Principal Authors:

William J. Betteridge-Electricore Inc

Electricore Inc.

27943 Smyth Drive, Suite 10.5

Valencia, CA 913.55

e-mail:William@electricore.org

David B. Quinn (Primary Technical Contact)

Earl W. Lankheet (Principal Investigator)

Delphi Corporation

MC 485-220-065

1601 N. Averill Ave.

Flint, MI 48556

810-257-5036;fax 810-257-2001; e-mail david.quinn@delphi.com

Report Issue Date: 25-April-2006

Modified: 14-August-2006

DOE Award Number: DE-FC26-01AL67634

\section{Submitting Organization:}

Electricore, Inc.

27943 Smyth Dr., Suite 105

Valencia, CA 91355

760-505-2909; main: 661-607-0260 fax: 661-607-0264

e-mail:william@electricore.org

Subcontractors:

Delphi Electronics and Safety, Kokomo, IN 


\section{$\underline{\text { DISCLAIMER }}$}

This report was prepared as an account of work sponsored by an agency of the United States Government. Neither the United States Government nor any agency thereof, nor any of their employees, makes any warranty, express or implied, or assumes any legal liability or responsibility for the accuracy, completeness, or usefulness of any information, apparatus, product or process disclosed, or represents that its use would not infringe privately owned rights. Reference herein to any specific commercial product, process or service by trade name, trademark, manufacturer, or otherwise does not necessarily constitute or imply its endorsement, recommendation, or favoring by the United States Government or any agency thereof. The views and opinions of authors expressed herein do not necessarily state or reflect those of the United States Government or any agency thereof. 


\section{Table of Contents}

Abstract............................................................. 4

Introduction..................................................... 5

Executive Summary ..............................................

Results and Discussion............................................ $\quad 8-29$

Conclusion....................................................... 30

List of Acronyms and Abbreviations............................... 31 


\section{ABSTRACT}

The Electricore/Delphi team continues to leverage the electrochemical planar sensor technology that has produced stoichiometric planar and wide range oxygen sensors as the basis for development of a NOx sensor. Zirconia cell technology with an integrated heater will provide the foundation for the sensor structure. Proven materials and packaging technology will help to ensure a cost-effective approach to the manufacture of this sensor.

The electronics technique and interface is considered to be an area where new strategies need to be employed to produce higher $\mathrm{S} / \mathrm{N}$ ratios of the NOx signal with emphasis on signal stability over time for robustness and durability. Both continuous mode and pulse mode control techniques are being evaluated.

Packaging the electronics requires careful design and circuit partitioning so that only the necessary signal conditioning electronics are coupled directly in the wiring harness, while the remainder is situated within the ECM for durability and costs reasons. This task continues to be on hold due to the limitation that the definition of the interface electronics was unavailable until very late in the project.

The sense element is based on the amperometric method utilizing integrated alumina and zirconia ceramics. Precious metal electrodes are used to form the integrated heater, the cell electrodes and leads. Inside the actual sense cell structure, it is first necessary to separate NOx from the remaining oxygen constituents of the exhaust, without reducing the NOx. Once separated, the NOx will be measured using a measurement cell. Development or test coupons have been used to facilitate material selection and refinement, cell, diffusion barrier, and chamber development.

The sense element currently requires elaborate interconnections. To facilitate a robust durable connection, mechanical and metallurgical connections are under investigation. Materials and process refinements continue to play an important role in the development of the sensor. 


\section{INTRODUCTION}

This project is developing the remaining technologies needed to deliver a robust NOx sensor for use in closed-loop control of NOx emissions in lean-bum engines such as compression ignition direct injection engines. At least two applications for NOx sensors have been identified: (1) for engine-out control of NOx, requiring a range of zero to $1500 \mathrm{ppm}$; and (2) for aftertreatment control and diagnostics, requiring a range of less than about $100 \mathrm{ppm}$ NOx. This activity builds on existing and developing Delphi technology in multi-layer and exhaust sensor ceramics. 


\section{EXECUTIVE SUMMARY}

\section{Project Objectives}

- Develop an electronics control circuit for the NOx sensor.

- Develop the packaging for the electronic controller (on hold due to project limitations).

- Develop the sensing element structure based on integrating zirconia and alumina ceramics and planar element technology.

- Develop the interconnection method to carry power and signal to and from the NOx measurement device.

- Develop the necessary materials and process refinements in support of the ceramic sense element.

\section{Approach}

- Use alumina and zirconia ceramic tapes and thick film screen-printed pastes to form the necessary control and measurement cells. Integrate the heater on the co-fired substrate.

- Initiate development using simple configuration test samples and coupons. Continue to evolve the design and test samples into a fully functional NOx measurement sense element.

- Confirm the operation of the sense element using bench and engine testing.

- Use Set Based Concurrent Engineering to develop alternative techniques to interconnect the power and signal wires to the sense element substrate. Use accelerated engine and environmental testing to establish the optimum interconnection approach.

- Use existing sensor packaging technology to house and protect the sense element.

\section{Accomplishments}

1. Developed several sample coupons with various cell configurations used for pump and measurement electrode screening.

- Demonstrated ideal separation performance on an electrode material, but this performance was limited to very low oxygen concentrations.

- Showed that a small addition of gold into the platinum electrodes severely reduces the oxygen transport capacity of the electrodes.

- Tested the NOx decomposition of various concentrations of doped Platinum/Au electrodes and determined initial stability

2. Developed a 4-cell sense element based on a NOx function model

- Fully characterized the impedance and temperature behavior of sensing element cells.

- Developed control point parameters for the individual cells in the sense element

- Evaluated cell performance durability with long term diesel exhaust exposure

- Successfully built 4-cell sense elements without delaminations and micro defects

- Improved sinterability of a highly complex NOx sense element

- Developed process for key separation electrode material

- Eliminated cross contamination of electrode materials through improved design 
- Successfully tested stability and durability of the separation electrode at elevated temperatures

- Transitioned to a new source of ceramic green tape and modified the production process to accommodate its unique features

3. Significant design and materials improvements were implemented

- Significantly reduced zero point accuracy and stability with ambient temperature changes

4. Designed a mechanical interconnection system.

- Successfully demonstrated direct welding of single and multiple (gang) nickel-coated copper wires to platinum substrate pads achieving an average tensile pull strength value of $11 \mathrm{lbs}$.

- Successfully demonstrated multiple direct ultrasonic welding. Ultimately this interconnection technique was dropped in favor of mechanical connection

- Implemented and improved 8-wire intercomection design

- Successfully passed hot vibration and shock testing an 8-wire mechanical connection equivalent to 200,000 miles of vehicle operation.

5. Designed and built an initial NOx sensor development breadboard controller.

- Evaluated sensor response capability for continuous mode and pulse mode measurements

6. Developed and evaluated the GEN I prototype electronic controller

- Initiated electronics control parameter refinement

7. A Gen II electronic controller was developed that incorporates electronic hardware and software improvements.

8. Demonstrated comparable signal measurement for both oxygen and NOx signals to a NOx reference sensor on a diesel engine dynamometer.

9. Demonstrated functional performance of a NOx sensor with over 20,000 vehicle miles accumulated.

\section{Future Direction}

- There are a number of sense element design refinements that should be implemented. Most of these refinements are "tweaks" to the design and materials to further improve measurement accuracy, response time, improved durability, and cost.

- Data suggest that another round of controls parameter settings should be performed with the latest version of sense element hardware.

- Process development for some key new processes is still required.

- Additional testing in the area of long term durability is required of the sensor.

- Continued development of the sensor and controller is required to make them production worthy 
Final Report-NOx Sensor

\section{RESULTS AND DISCUSSION}

\section{Background:}

Figure 1 shows a starting functional diagram of a NOx sensor. This structure consists of layers of zirconia and alumina ceramics with appropriate electrode materials constructed to yield three distinct cells, a first oxygen separation cell, where the incoming exhaust sample is separated by means of pumping oxygen, so that only NOx components are remaining. The second cell is used to monitor and control the first cell. The third cell is for the measurement of the NOx in the exhaust sample by means of reducing the NOx and monitoring the corresponding low current levels that result. The integrated heater and other structure are not shown for clarity. This functional diagram is useful in understanding the principle of operation, but does not reflect the true design of the NOx sensor. The following results are grouped under the headings of the five main tasks below.

NOX SENSOR FUNCTIONAL DIAGRAM

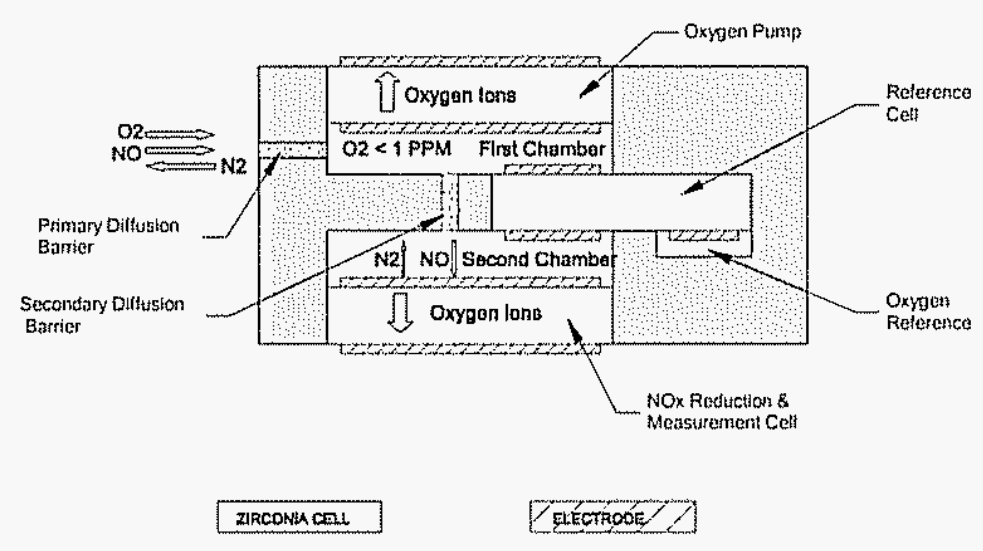

Figure 1. Functional diagram of a NOx sensor

\section{Task 1: Develop an electronics control circuit for the NOx sensor.}

Set Based Concurrent Engineering (SBCE) is a technique that was used in the development of the electronic control of the NOx sensor. SBCE is really no more than a parallel path approach to solve a technical or engineering problem, mostly to reduce the risk of selecting a path that may have a significant barrier to success. By using a dual path, the options usually have a lower and a higher risk. The higher risk approach usually offers a better "pay-off" of performance or cost with an unproven design. The lower risk usually offers a more moderate pay-off but may be more practical or easier to implement. The idea is to work on both approaches for as long as possible until any "show-stoppers" are discovered. Then the focus is on the remaining method, or a new alternative method is sponsored to continue the dual path.

The intent in this project was to start off with two strategies for electronic control. The first is known as continuous mode. In this method, the sensor continually measures the NOx concentration, requiring that the oxygen concentration is kept at or near 0 ppm levels. 
The second strategy is to employ Differential Pulse Voltammetry (DPV). With DPV, the NOx measurement cell is pulsed with low voltage to establish oxygen concentration levels or the baseline, followed by a high voltage pulse, which would account for both Oxygen and NOx concentration. The difference in the two values would be the level of NOx at any given time. An example of this is described below.

A voltage can be applied to the pump cell and the current can be monitored to produce a cyclic voltammetry (CV) curve like that of Figure 2. One series is plotted where background oxygen is the only gas being measured. When $500 \mathrm{ppm}$ NOx is added to the sampled gas, a second series is plotted. This graph shows the behavior of an ideal NOx sensor electrode. At lower applied voltages, the electrode in the pump cell does not reduce the NOx component. At higher voltages, both the NOx and the oxygen are reduced. Once the oxygen is separated and removed from the exhaust sample, the measurement of NOx concentration can be made. This separation behavior is required over the full range of operating conditions, and needs to be very stable over time. The results achieved show excellent behavior, but this has only been obtained at very low oxygen concentration levels with corresponding low oxygen pumping current levels. At higher oxygen concentration levels $(>0.1 \%)$, the pump cell cannot effectively pump all of the oxygen, leaving some oxygen to confuse the measurement cell resulting in an inaccurate measurement. The reasons for this low pump efficiency are explained later in the report.

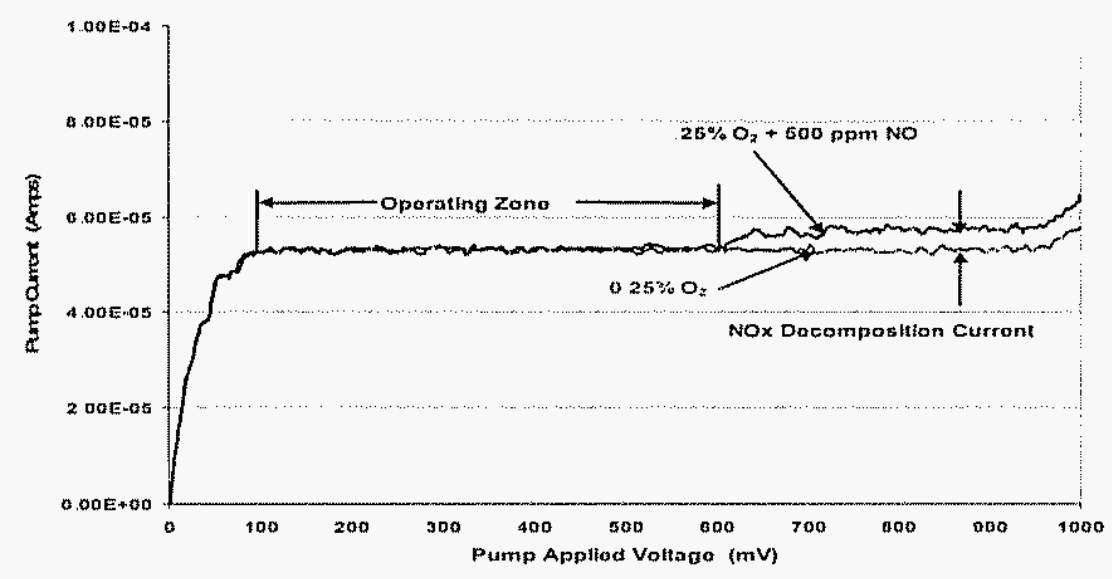

Figure 2. CV curve of an ideal behavior NOx electrode

The original premise of DPV control was to obtain much higher NOx sensitivities (high output). This has been shown to be true through experimentation. Figure 3 below shows the output vs. frequency for a cell using DPV. While it is true that a much higher output signal was achieved at the higher frequencies, however, the current sensitivities were non-linear with NOx, they were not reproducible or predictable from sample to sample. In addition significant oxygen cross sensitivity was encountered. Sensor response rates were highly variable under pulsed mode over a number of sensor builds, designs, and configurations. It is believed that sensor electrode parameters such as concentration, thickness, surface area, porosity, etc., are responsible for this variation. It is estimated that the response for a single pulse needs to approach that of about $50 \mathrm{mS}$ for this technique to be useful. The best combination to date has been measured at $-100 \mathrm{mS}$ 
In order to take full advantage of the DPV method, the science governing its operation had to be better understood. Impedance spectroscopy methods were used to develop models of the electrochemical system encompassing the electrode and electrolyte. In the desirable operating frequency range of 5 to $50 \mathrm{~Hz}$. the models revealed that surface diffusion of NOx on the electrode surface is the controlling function. Much work would be required to properly understand how the NOx surface diffusion rate is controlled by NOx concentration as well as the physical parameters of the electrode and oxygen concentration. The time and facilities required to perform a proper investigation exceeded the project resources and success was not guaranteed. For these reasons, the continued investigation of DPV was placed on hold. Therefore, resources were placed on the continuing development of the continuous mode control method.

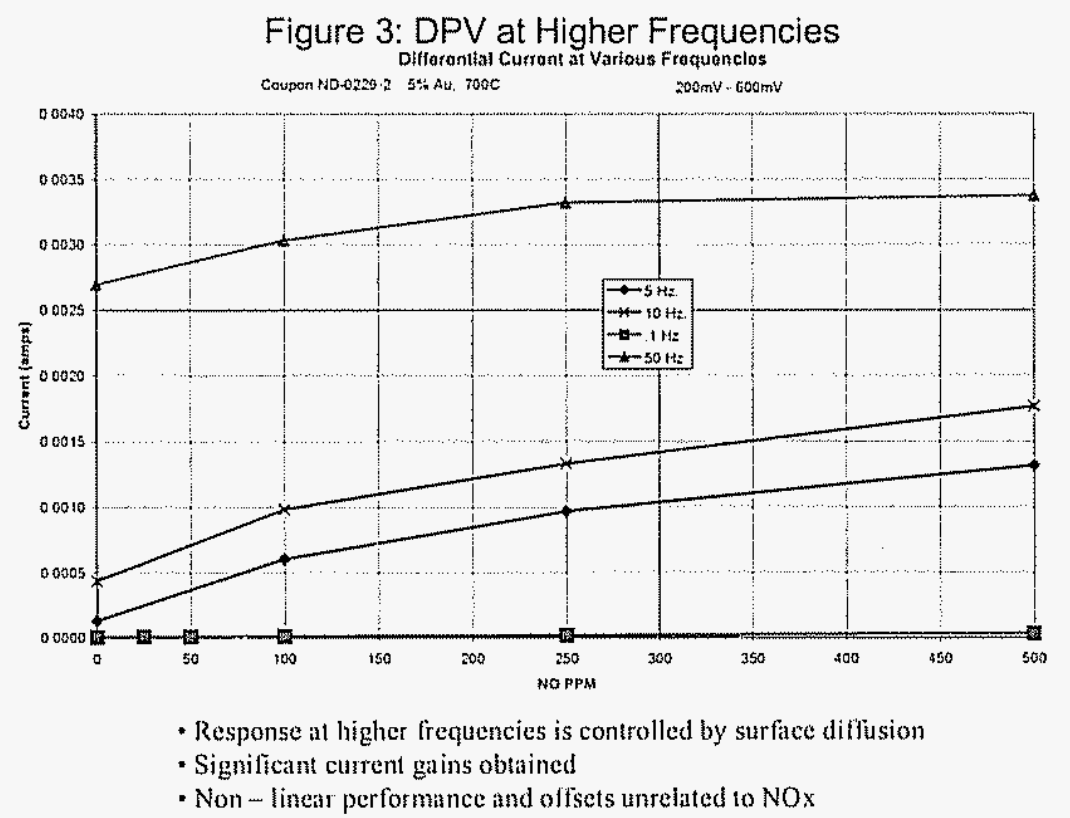

A NOx sensor breadboard development controller was designed and constructed and is shown in Figure 4. This controller operates each of the sense elements cells and the heater, as well as, houses the necessary interface and diagnostics of the sensor. The controller has been evaluated and functions as expected. Based on the successful use of this breadboard version, the Gen I electronic controller was designed and built. 


\section{NOx Sensor breadboard}

Figure 4

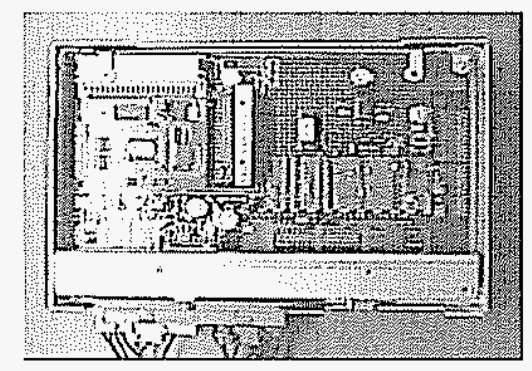

The Gen I electronic controllers were developed based on the continuous mode control and are pictured in Figure 5. The circuit is designed to control the heater, all of the cell functions and provides oxygen and NOx concentration signals. The packaging of the controller is sufficient to allow the use of the sensors for initial performance and durability studies on both vehicle and dynamometer engines. Twelve of these controllers were built during the project. The controller consisted of three circuit boards to make use of existing circuitry from other sensor programs. The controller supports CAN interface and analog outputs. Fully functional NOx sensors with Gen I electronic controllers were characterized on the gas bench, calibrated and then run on a diesel engine dynamometer and vehicle. They served the purpose of allowing for monitoring and control of development NOx sensors. As they were used, a list of refinements to control was established to become part of the Gen II specification of the controller.

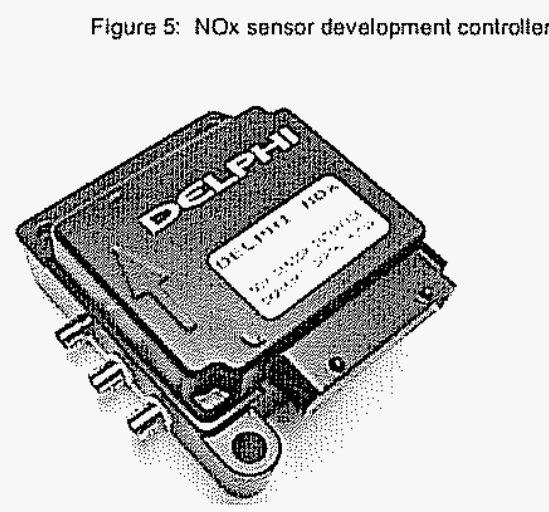

Figure 6 illustrates the Gen II controller. This controller represents the next generation of control for the NOx sensor. It has both hardware and software improvements. It is meant to be a controller capable of supporting prototype testing across vehicle, bench, or dynamometer. The controller has developed from a three circuit board design to a single board. A new microprocessor was implemented that has re-useable software architecture. The controller has an additional CAN channel to support instrumentation and vehicle needs, concurrently. Additional improvements have been made to the heater warm-up routine and cell control techniques. The sampling rate was increased for temperature feedback, to allow for better control during transient conditions. Other improvements 
are: lower noise in the output signal and improvements in cell diagnostics. The controller has been evaluated on the bench and dynamometer and has performed as expected. Additional data is reported under Task 3.

Figure 6. NOx sensor Gen II controller

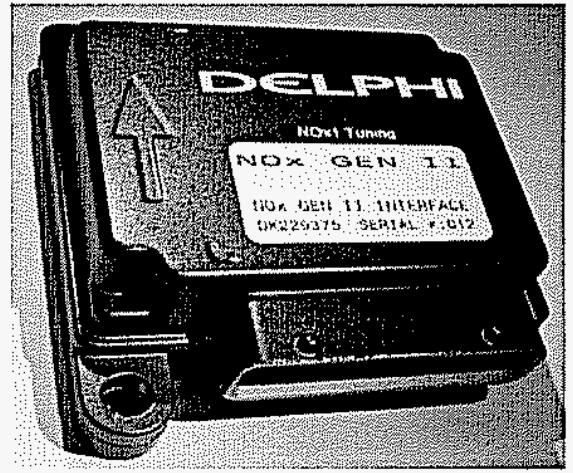

\section{Task 2: Develop the packaging for the electronic controller}

When this project was written it was always expected that this task would be performed later in the project life cycle, for the simple reason that it is extremely difficult to design a package for something that does not exist. As the project continued, meetings were set up to discuss options for the production packaging of the sensor electronics. The obvious trade-offs of performance and costs were a key consideration of these discussions, however due to the late development of the NOx sensor circuitry, evaluation, and verification, this task did not proceed beyond the discussion stage. The next steps would have been to continue on with this development with the study of how to partition and where to locate the necessary electronics in the subsystem. It is known that some of the electronics would need to be housed very near the sensor. Other circuitry could be moved to the best location for it, whether it is the sensor connector body, a stand-alone module, or incorporated directly into the ECM. This task will have to be recommended as a future step in the development of a production version of the NOx sensor.

\section{Task 3: Develop the sensing element structure based on integrating zirconia and alumina ceramics and planar element technology}

The sense element of the NOx sensor is comprised of multiple ceramic layers of alumina and zirconia ceramics. These layers have features, e.g. electrodes, leads, heater serpentine, diffusion channels printed on them to ultimately form the desired structure of the sense element. Via's are small holes which are punched through the ceramic tape, later to be filled with precious metal to bring the power and signal from the interior of the element to the exterior. Other features in the device include chambers, contact pads, and air channels. 
The printed layers are oriented layer by layer and "stacked" appropriately to build up the device. The layers are then consolidated using a lamination process, which applies both pressure and heat to mold the layers together. The sensors are each cut from the larger "tile" into individual elements prior to sintering. There is a great deal of ceramic and thick film design and processing expertise required to form the complex features of the NOx sensor. Sintered NOx sense elements are illustrated in Figure 7.

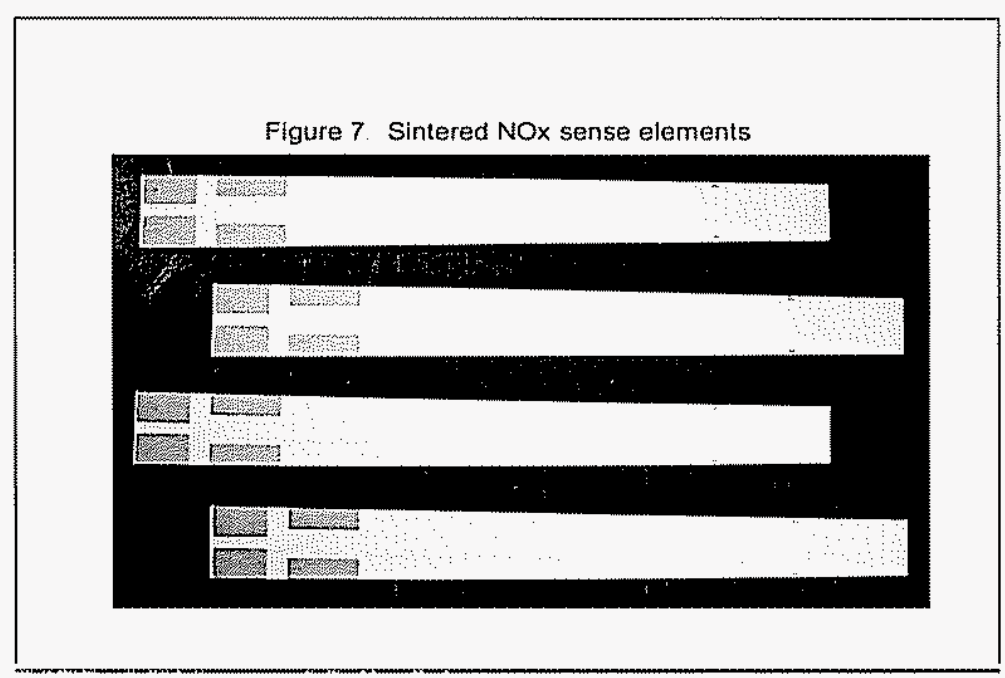

Figure 8 shows the initial performance of a NOx measurement cell. NOx reduction current is plotted versus, the applied voltage to the NOx measurement cell. The NOx levels were varied between 0 and $500 \mathrm{ppm}$ NO. The NOx measurement can be obtained at a cell operating voltage of about $750 \mathrm{mV}$, and is directly proportional to the NOx levels. Continued refinements to the NOx electrodes and element design and control parameters should allow for improvements in current limiting of the cell thus increasing sensor resolution and accuracy. 


\section{Figure 8 NOx Measurement Cell}

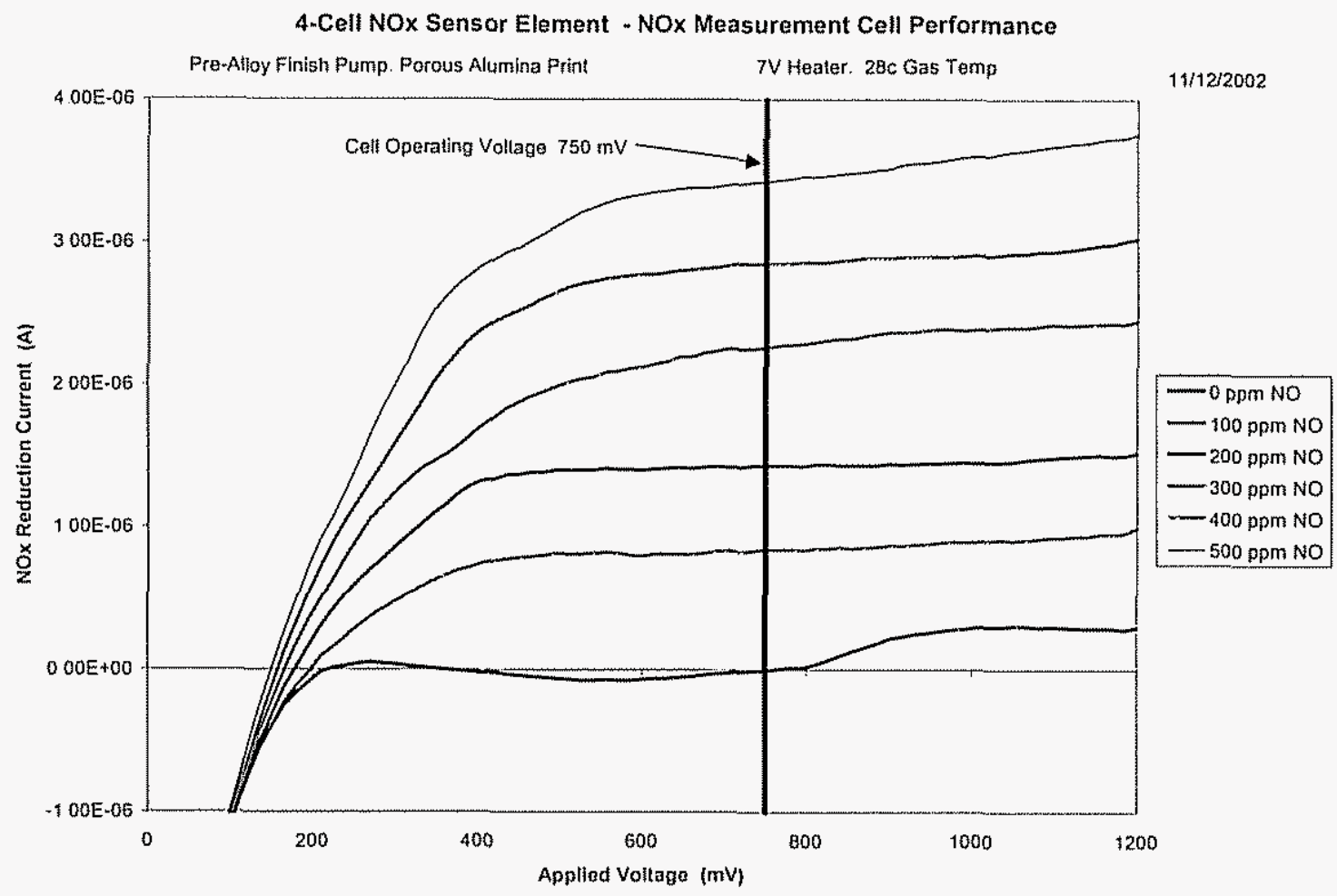

Figure 9 shows the proposed assembly package to house the sense element. This assembly package is very similar to that of other planar sensor element housings that have been proven to be durable to the exhaust environment and cost effective to manufacture. The packaged sensors can be connected to the NOx controllers and mounted onto an exhaust pipe for testing. The initial testing of the NOx sensor was on a 1.91 diesel engine running in a dynamometer site.

Figure 9: NOx Sensor Assembly

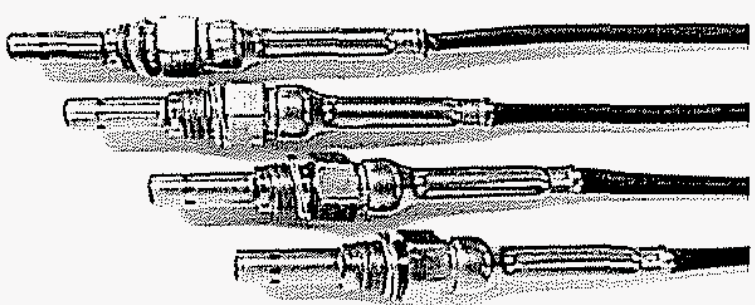


Figure 10 shows the oxygen concentration signal of the sensor mounted in an exhaust pipe in the engine out location. An oxygen analyzer is used as a reference. When the data is time aligned (to account for transport time) and filtered, it can be seen that the oxygen concentration signal from the NOx sensor correlates well with that from the analyzer. The EGR level was varied to create the different levels of oxygen and NOx concentrations. Note that the sensor has a much steeper transition compared with the analyzer at the step changes in EGR, indicating a faster response.

Figure 11 shows six EGR step changes with similar results from the oxygen concentration signal of the sensor. Figure 12 shows the NOx response through six EGR step changes. The NOx levels varied from about $250 \mathrm{ppm}$ NOx to about $450 \mathrm{ppm}$ NOx. In general, the NOx sensor correlates very well with the NOx analyzer. There are a few areas on the graph that have less correlation between the sensor and analyzer. This may possibly be attributed to the transport time and any mixing of the gas.

Figure 10: Oxygen Measurement - dyno

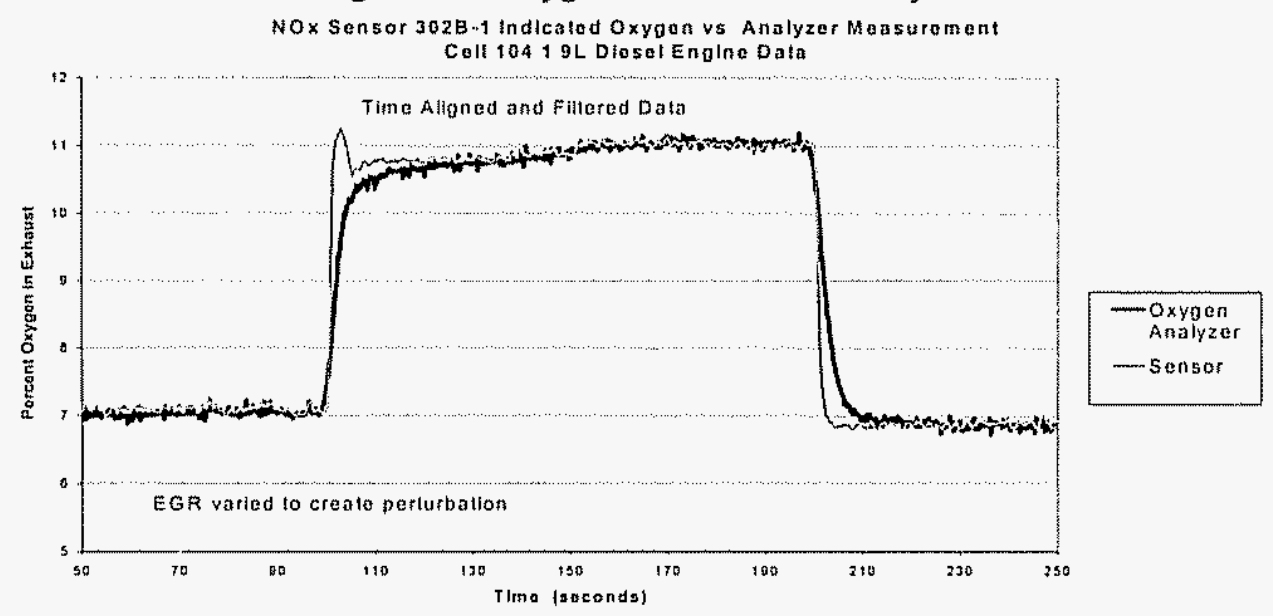


Figure 11: Oxygen Measurement - dyno

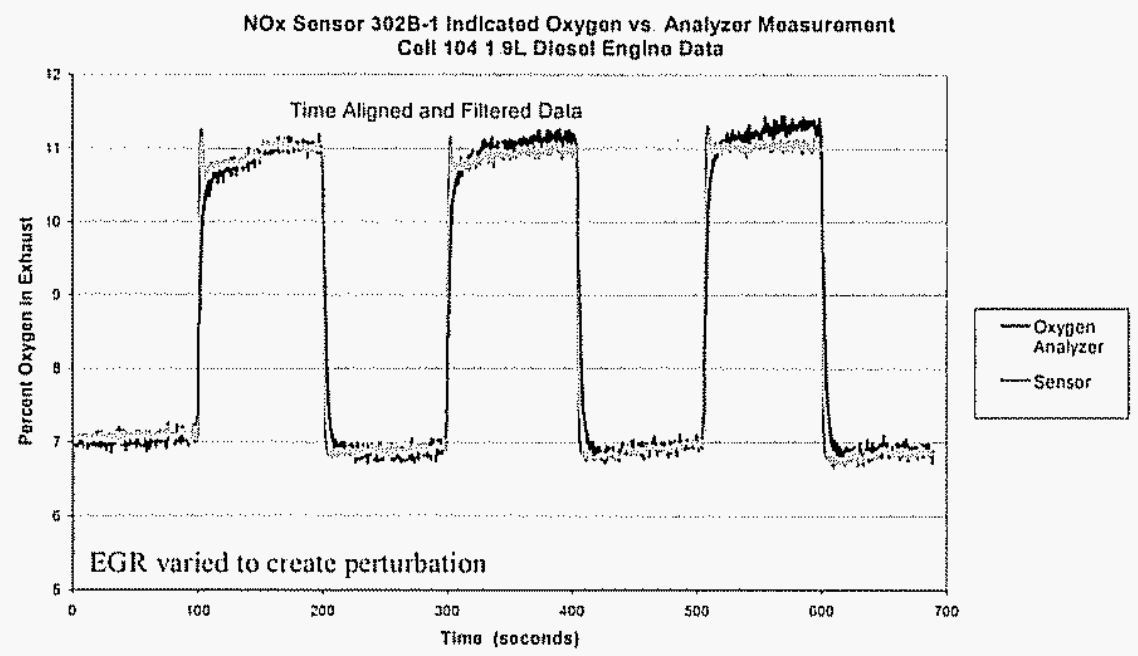

Figure 12: NOx Measurement - dyno

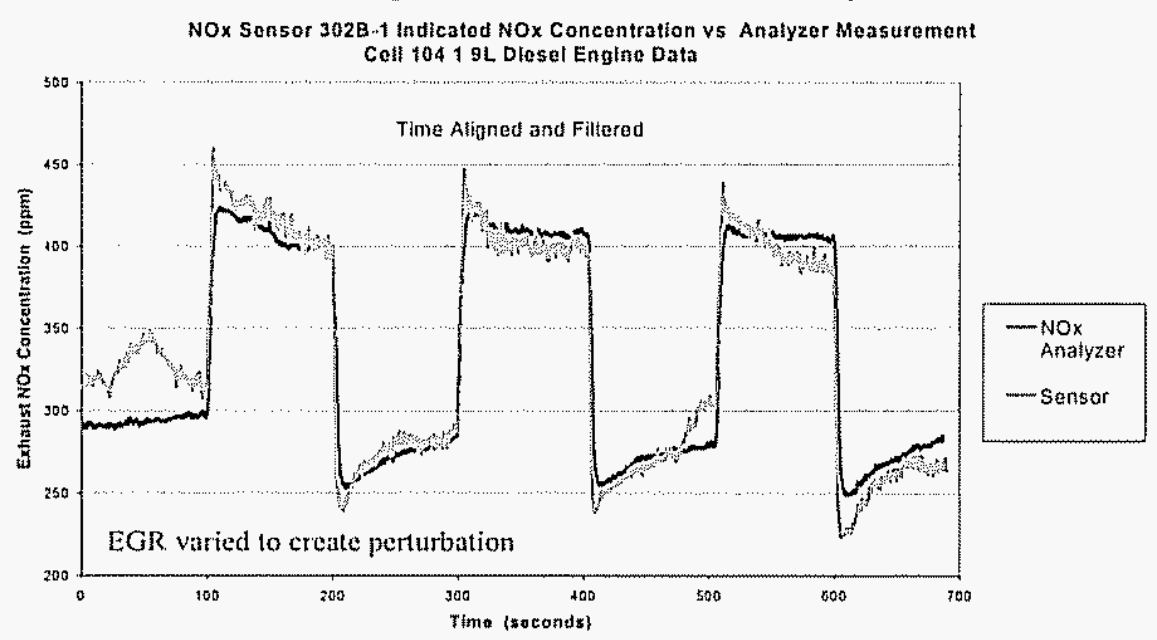

Sensors were located in both engine out and post catalyst positions as shown in Figure 13. Both the Oxygen and NOx signals were recorded and compared with a competitive sensor for reference. The sensors were evaluated using a thirteen-step mode driving cycle. Figure 14 compares the oxygen signal from the Delphi sensor with a reference sensors oxygen signal over the twenty-eight minute test. The two signals are essentially identical throughout the entire test. The NOx signals were also compared to the reference sensor and are shown in Figure 15. Overall, there is good general agreement between the two sensors, but there are times when the Delphi sensor reports higher NOx than the reference sensor and other conditions when lower NOx is reported. These results sponsored a more detailed study of accuracy of the sensor. 


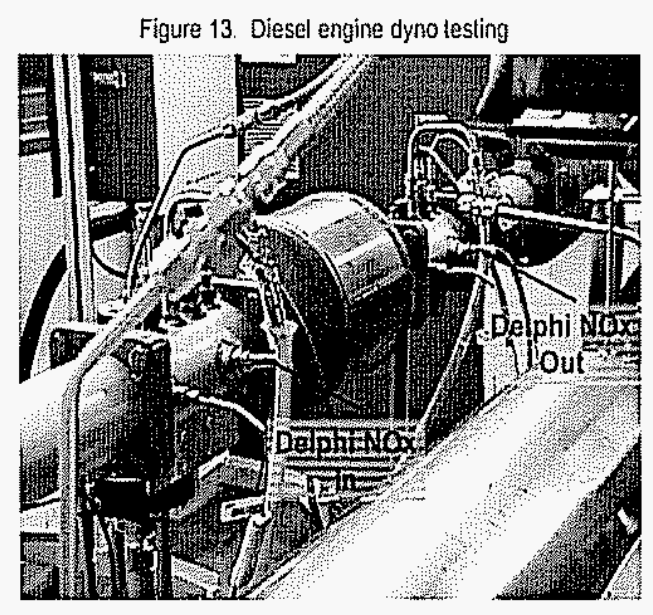

Figure 14 Diesel engine dyno - oxygen

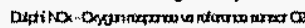

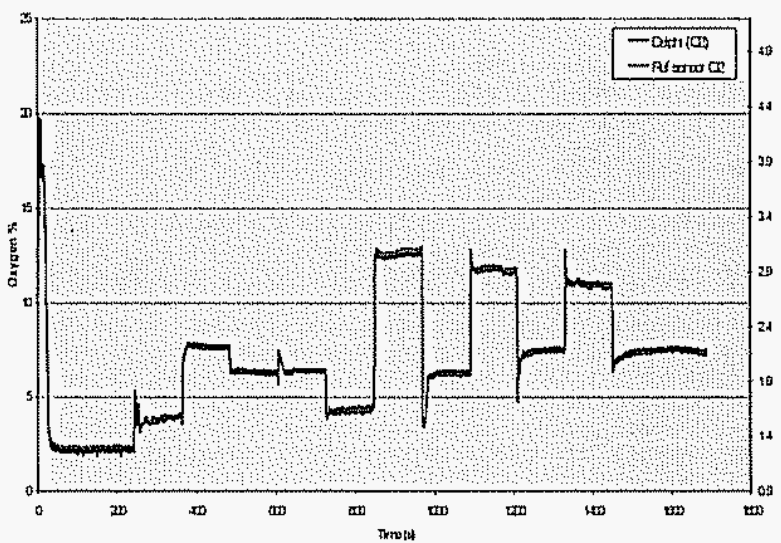

A NOx sensor was also placed on a diesel passenger car to accumulate typical road miles. The sensor was characterized before installation on the vehicle and from time to time as mileage accumulated. The first sensor and controller system accumulated over 7500 miles before it was decided to upgrade to more current hardware levels of the sensor and controller. The second system, comprised of a NOx sensor with Gen I electronics, has been on the vehicle for over 20,000 miles with the sensor still functional. A NOx sensor was also placed on a diesel passenger car to accumulate typical road miles. The sensor was characterized before installation on the vehicle and from time to time as mileage accumulated. Figure 16 shows the original gas bench NOx output versus the output after 10,000 and 20,000 miles on the vehicle. Although, the output appears to have "shifted" down, the slopes of all three curves are identical with no loss in gain of the signal. No significant change in performance was observed between 10,000 and 20,000 miles. 
NOx sensor output vs vehicle mileage

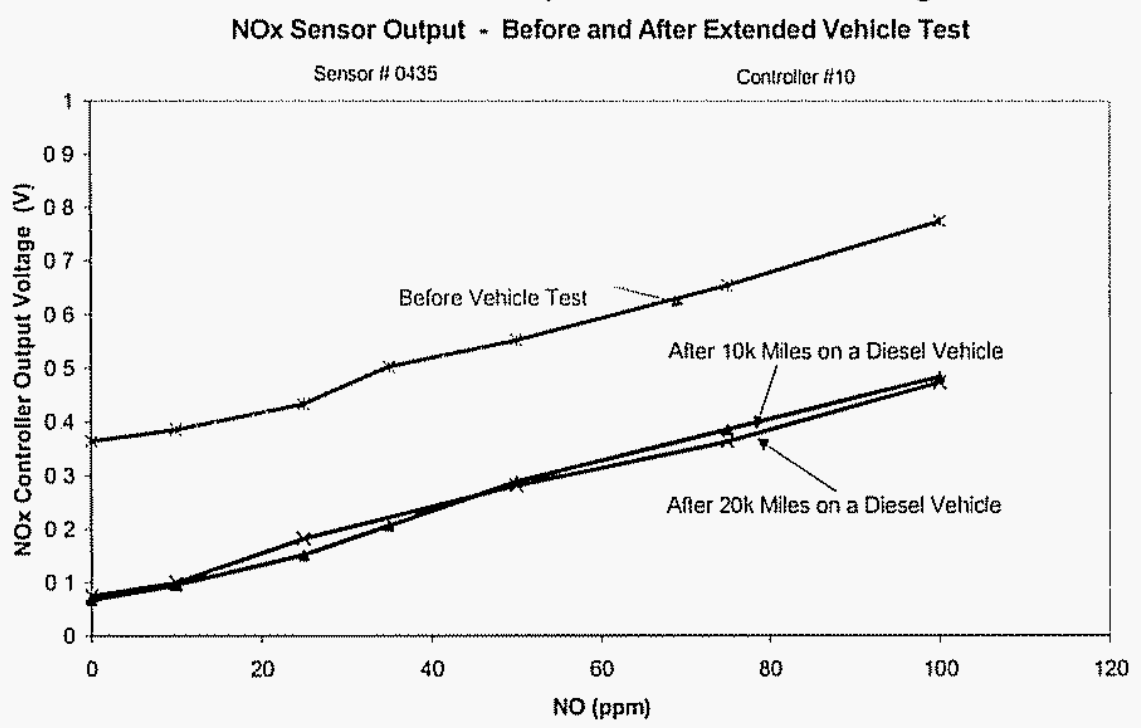

NOx sensors were characterized on a gas bench to determine causes for inaccuracies in the area of 0 to $25 \mathrm{ppm}$ NOx. One of the largest areas of error was related to a zero point offset. The offset at 0 ppm NOx has ranged from about 125 NanoAmps to as much as 800 NanoAmps on some sense elements. A root cause analysis of the elements was made and a major cause of error was found relating to the structure of the element. It was also determined that the error grew in significance with an increase in ambient temperature as shown in Figure 17(Sensor design A - Worst of the Worst "WoW" and Best of the Best "BoB"), Sensor design A represented a typical NOx sense element for the mid 2005 period. Sensor design A "WoW" shows a zero point offset of roughly 150 NanoAmps at room temperature and as the exhaust gas temperature is increased it more than doubles the output. Sensor design A "BoB" was derived from a sort process and is classified as a Best of the Best element. It has both a lower room temperature zero point offset and a less dramatic increase in output with temperature until about $250 \mathrm{C}$ where there is a large increase in output with increasing temperature. Sensor design $\mathrm{B}$ incorporated a number of materials and design modifications which were meant to increase the stability of the sensor output versus temperature. The sensor does have a low zero point offset at room temperature and it shows excellent stability throughout the ambient gas temperature range tested. These modifications will become part of the standard design going forward. 
FIGURE 17

NOx Cell Zero Current Stability

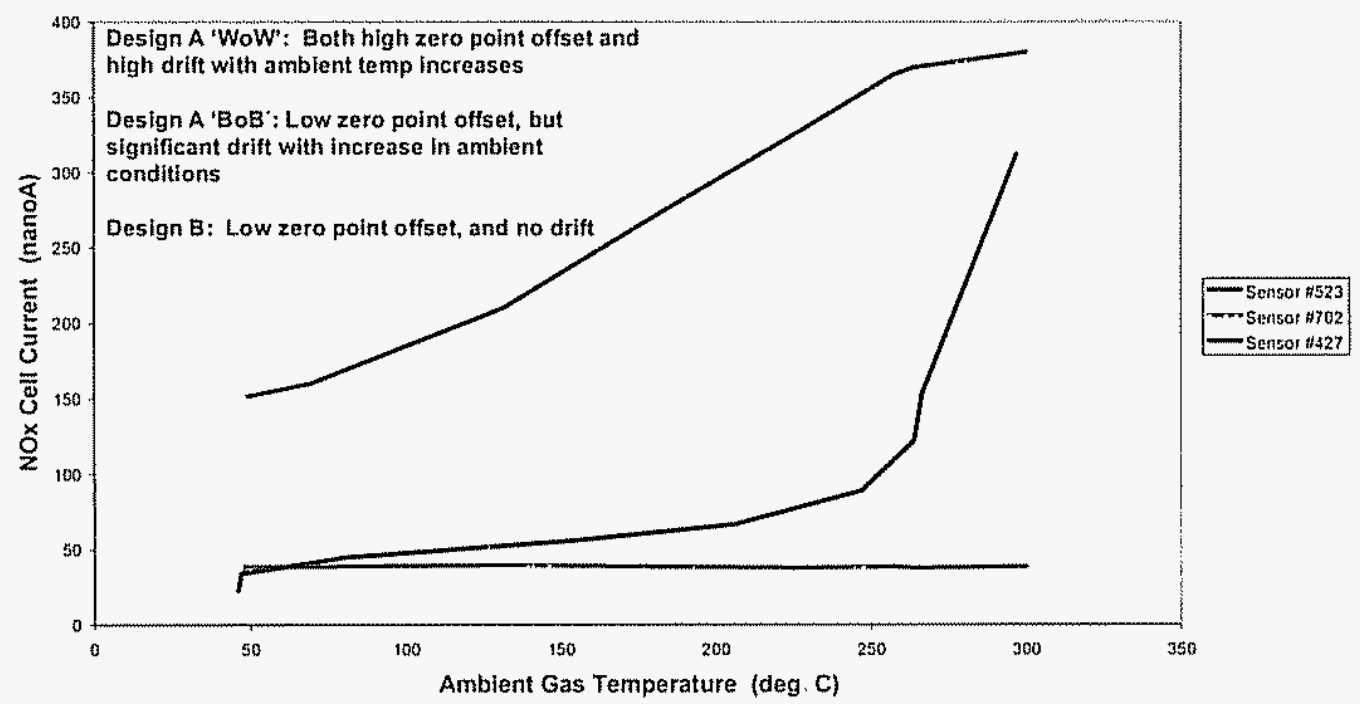

A NOx sensor was installed on a Diesel vehicle that was undergoing testing in a Vehicle Emission Laboratory. Figure 18 shows typical data that was collected from the oxygen signal output of the NOx sensor. Also plotted is another oxygen sensor for reference, and the output from the oxygen analyzer on the emission bench. All three signals show very good agreement.

FIGURE 18

VEL Oxygen Signal Data

Oxygen Signal Performance - Vehicle Data from Vehicle Emission Lab Test

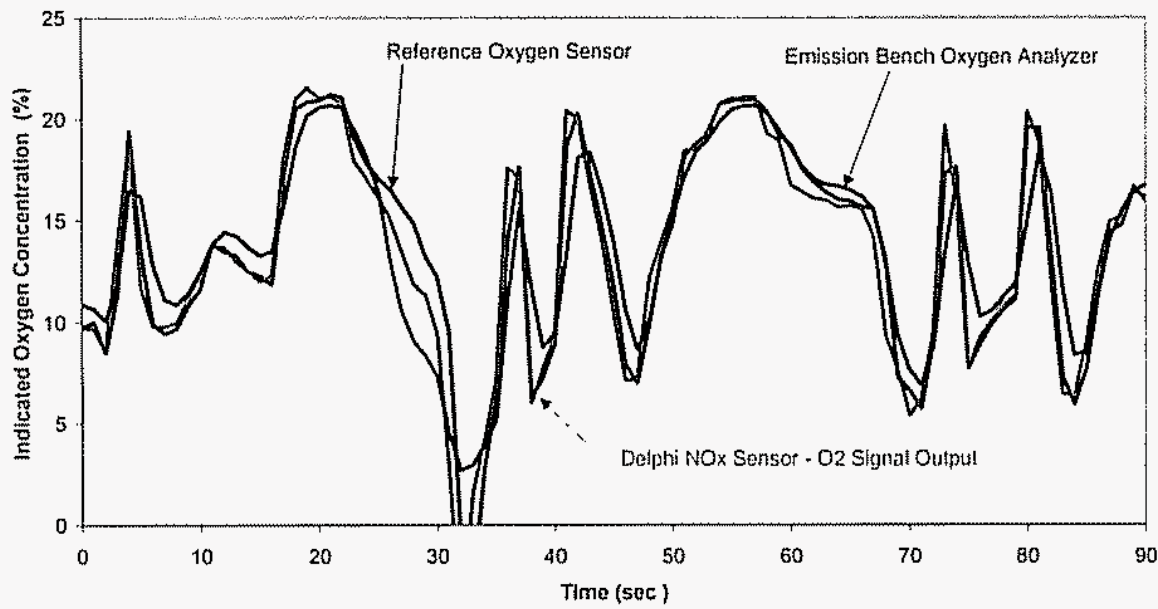


Figure 19 shows typical NOx signal output data from the VEL, test. All three signals show very good agreement for relatively low NOx concentrations

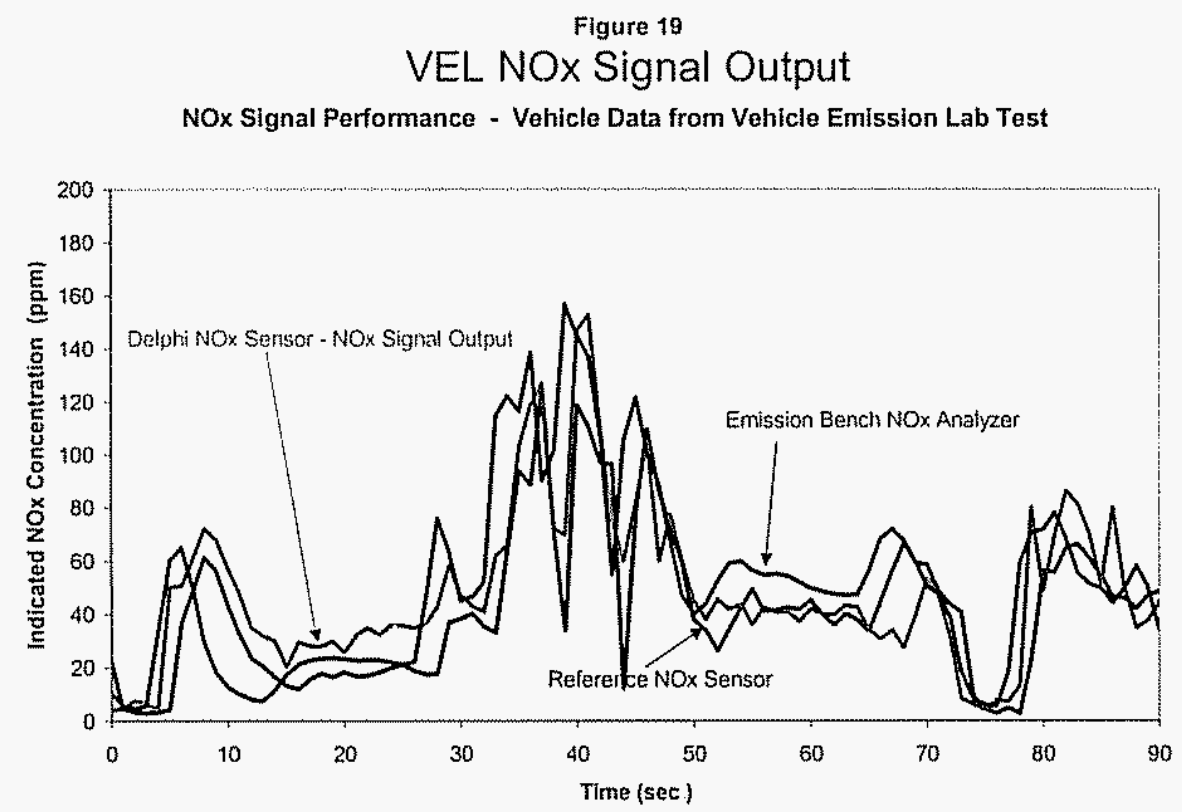

Task 4: Develop the interconnection method to carry power and signal to and from the NOx measurement device.

There are several package features that call for tailoring the design to meet the new requirements imposed by the NOx sensor. A key part of the sensor technology requiring development is the interconnection of the sensor signal wires to the sense element contact pads. The interconnection area needs to effectively house and protect the signal and power connections to the substrate. This comnection needs to be robust to temperature, vibration, and shock and continue to maintain signal continuity. The interconnection technique for the NOx sensor is more difficult due to the limited space available. Due to the increasing number of connections (8), it is necessary to have very compact and effective terminations/interconnections and suggests the use of (SBCE) to minimize the risk. Various techniques were evaluated. Among these were, mechanical connection, brazing, and direct welding of the wires to the sensor pads.

The primary two techniques being developed for interconnection are mechanical and direct welding. Figure 20 shows a concept for the mechanical connection. It involves metal terminals connected to 
each of eight wires that are spaced apart by a ceramic component. The mechanical connection is designed in such a way that the sense element substrate is simply inserted between the two halves of the connector and then a metal spring clip is placed around the ceramic that transfers a normal force to each of the terminals making contact with the substrate pads. Sufficient normal force is used to ensure that a connection is maintained over the required operating temperature range.

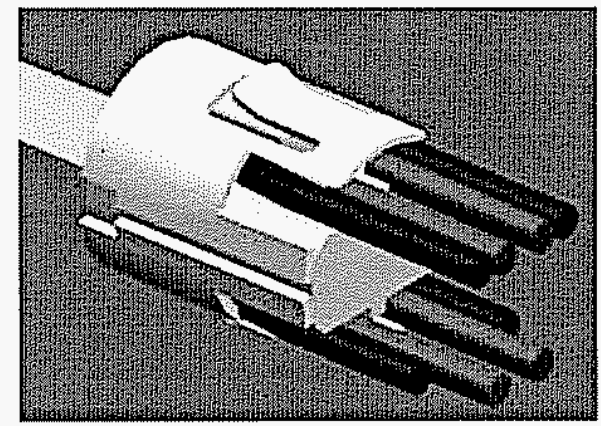

Another technique for connection is the direct welding of stranded wire to the platinum pads of the substrate illustrated in Figure 21. Prior to direct welding, the stranded wire must be preconsolidated, that is, to bond each of the individual strands of wire together.

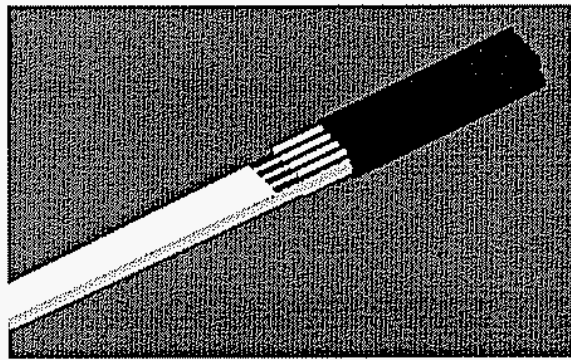

Figtire 21

Direel welding of nickel-conted copper wires to platinum pads on an alunina substrate 
Figure 22 demonstrates the pre-consolidation step that enables the 19-strand wire to be formed into a rectangular shape to facilitate welding.

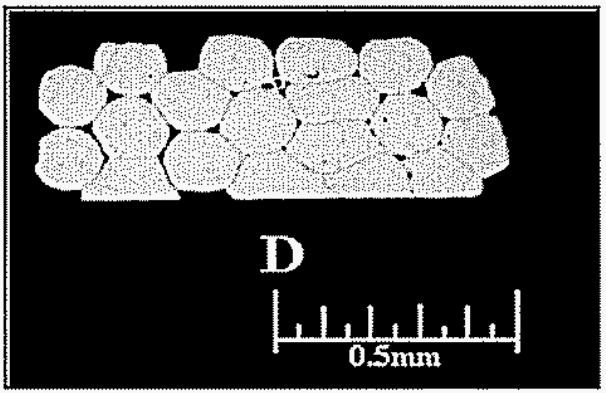

Figure 22

Wire Pre-consolidation prior to welding

Figure 2.3 shows the wire/platinum pad interface from a polished cross section as seen by optical microscopy. A tensile test on ultrasonically welded lead wires to the platinum pads has yielded average pull strengths of $11 \mathrm{lbs}$, which is considered to be sufficient for this application.

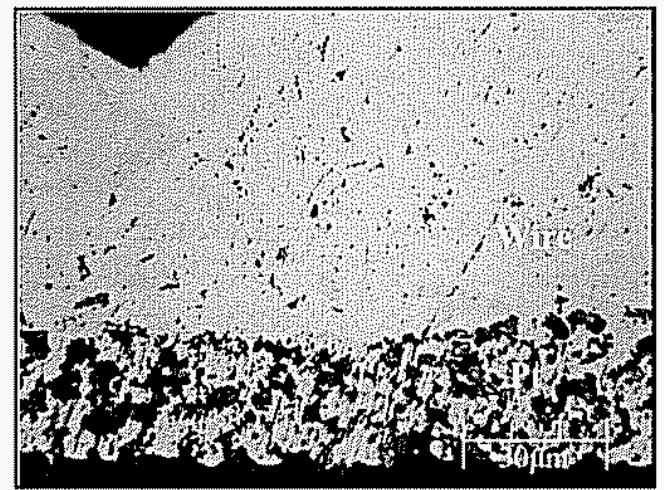

FIGURE 23

Welded wire - platinum pad interface 
Figure 24 shows an example of one side of the sense element fully connected using direct welding. The direct ultrasonic welding process has continued to develop and demonstrated that multiple welds can be achieved with this technique. Although interconnection development has progressed with both of the SBCE designs, several process issues have been identified with the direct welding method that indicates the cost of this technique would be substantially higher than mechanical connection. This is due to the complexity of this process and the tooling required making it highly unlikely as a production solution. Therefore, the interconnection scheme being used is a mechanical connection. It has been proven to be more robust and is adapted from production sensors.

Figure 24 DIRECT WELDING

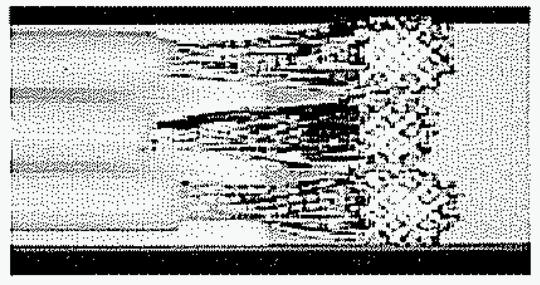

A critical test for the interconnection and overall package is a vibration and shock test. This severe test comprises, cycling the exhaust temperature from about $150^{\circ} \mathrm{C}$ to about $950^{\circ} \mathrm{C}$, while running 2 axis, vibration (sine wave, and random) simultaneously. The accelerated test is meant to simulate 200,000 miles of vehicle/engine conditions. Figure $\mathbf{2 5}$ shows a typical vibration and shock test at the high temperature where glowing exhaust pipes can be seen. Five sensors were tested for hot vibration and shock, representing 40 individual connections. All of the interconnections maintained continuity throughout the test.

Figure 25

Hot vibration \& shock test

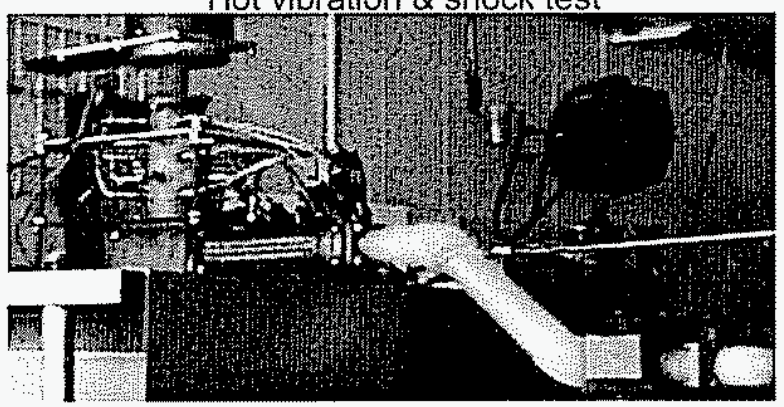


Task 5: Develop the necessary materials and process refinements in support of the ceramic sense element.

Most of the materials development supporting this project involved the construction of the sense element and the development of electrodes that were optimized to carry out their specific function in the sensor. Various configurations of test coupons were created throughout the project to study electrode behavior. Figure $\mathbf{2 6}$ shows some of these special test coupons. These test pieces are very simple to fabricate, focus on the electrodes and little other sensor geometry, and allow for a quick turn of testing to evaluate performance

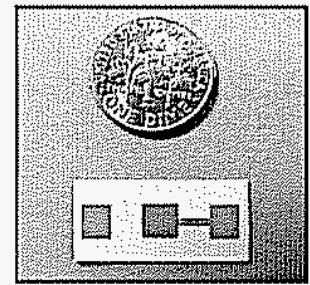

(a)

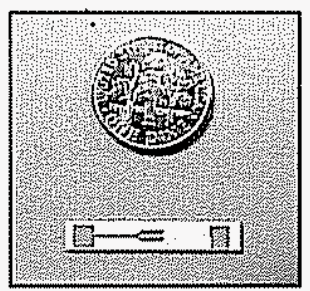

(b)

Figure 26

Development sample test cotıpons (a) open faced, and (b) diffusion limited

The Isothermal gas bench shown as Figure 27 was used to perform the studies. This bench allows for multiple test coupons to be lowered into a furnace so that steady state conditions can be simulated. It is an ideal setup for isolating electrode behavior.

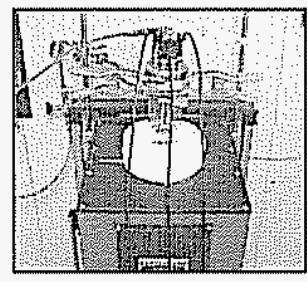

(a)

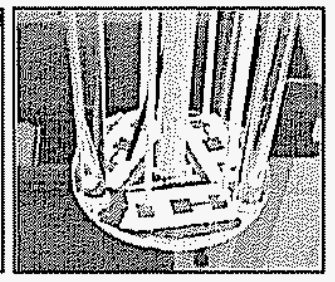

(b)

Figure 27

Sample coupons mounted in a gas bench test tixture (a) gas bench fitrnace, (b) Quartz fixture showing sample coupons 
A key feature of the NOx sensor is the requirement for pumping oxygen without reducing the NOx component in diesel or automotive exhaust gas. Figure 28 plots the electrode current capacity versus temperature for candidate NOx separation and measurement electrodes fabricated using a thick film printing method. Two of the electrodes tested contained low levels of gold (red and blue graphed lines). Gold has been found to suppress NOx reduction at low applied voltages. It can be seen that even low-level additions of gold significantly reduce the electrode current capacity normally achieved with a platinum electrode (black line). This explains the electrode problem reported earlier with separation of NOx at higher oxygen concentration levels.

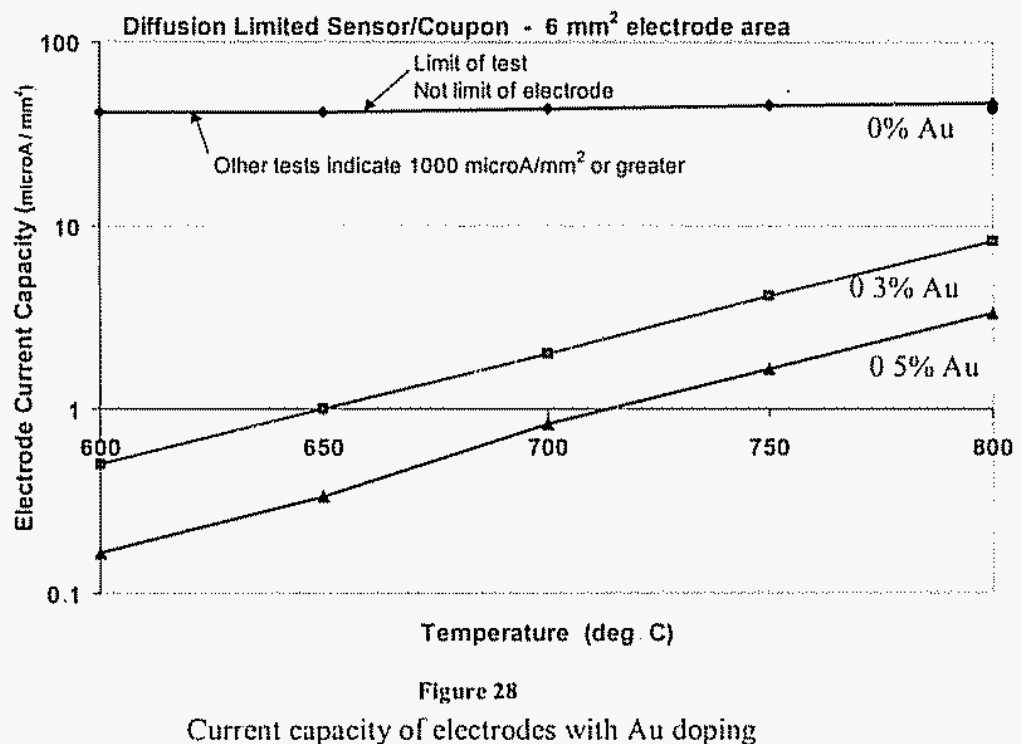

The impact of gold addition to platinum electrodes was also studied with sputter deposited thin film electrodes. The sputtering process provided an easy means of obtaining a wide range of gold concentrations. Figure 29 plots the significant increase in electrode interface impedance that occurs when gold is added to the platinum. Even a small amount (such as $0.5 \% \mathrm{Au}$ ) is seen to increase the impedance by 50 times. This would also reduce the oxygen pumping capacity of the cell by a factor of 50 .

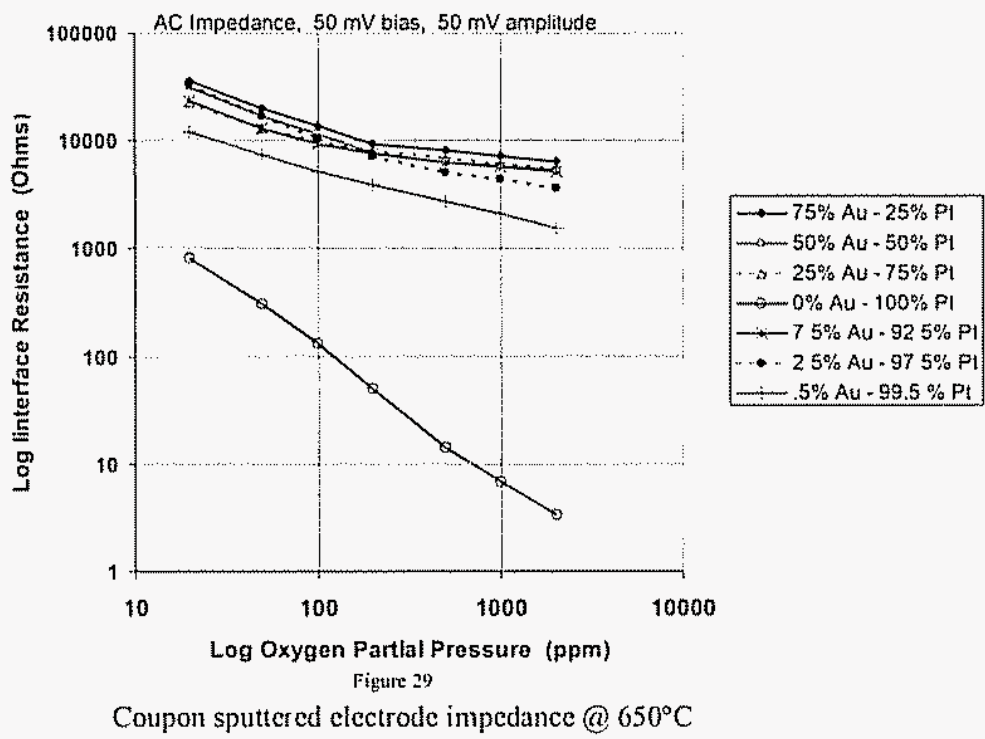


Figure 30 shows the NOx decomposition performance of pure Platinum and Platinum electrode materials doped with increasing amounts of Au. The doped electrodes delay or prevent NOx decomposition even at elevated temperatures compared with the pure Platinum electrode. These materials were re-tested after aging at temperatures as high as $950^{\circ} \mathrm{C}$ for 96 hours. The best electrodes were those processed in a slightly reducing atmosphere and demonstrated excellent stability throughout the aging experiment.

Earlier discussion indicated that doping the Platinum electrodes with Au severely diminishes the oxygen pump capacity of these electrodes, thus rendering it un-useable to perform the required separation of oxygen and NOx at anything but very low levels of oxygen. These results were taken into account when design of the sense element is concemed. An initial design incorporating 4-cells has been developed with the following features: a primary oxygen pump cell and a reference cell to control this rough pump located in a first sampling chamber, a small diffusion path connects the first chamber to a second chamber. Inside the second chamber exists a secondary or finish oxygen pump, and the NOx measurement cell. Air channels provide an oxygen reference and remove the pumped oxygen from the chambers. This design is an improvement over previous efforts, because even high levels of oxygen can be pumped from the first chamber using the rough pump, without reducing the NOx. The balance of oxygen and NOx is free to continue to the second chamber, where the finish pump electrode can pump the remaining oxygen without reducing the NOx.

In processing the initial 4-cell design, it was determined that the finish pump cell electrode (containing some $\mathrm{Au}$ ), was contaminating the NOx measurement electrode. Because the sintering process is a high temperature process, some material in the electrode composition can become mobile or vaporized thus contaminating the other electrode. The solution to this has been to move the NOx measurement cell and electrode into another chamber thereby shielding it from this phenomenon. Additional materials development for the NOx measurement electrode has provided a more robust electrode.

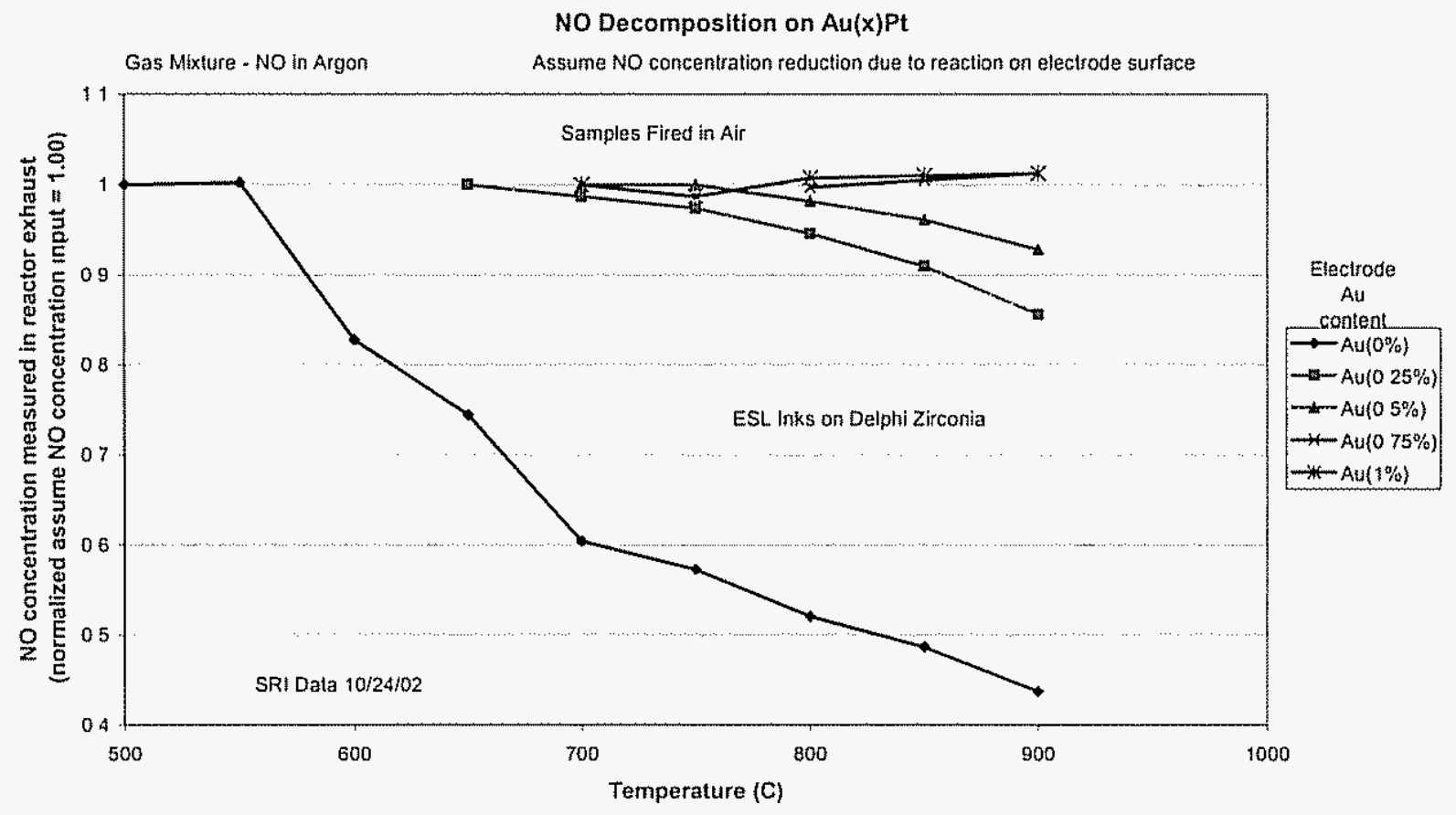

Figure 30: NOx Decomposition Performance 
One cell of the device plays a special role in keeping the oxygen in the measurement chamber at 0 ppm. This needs to be accomplished without reducing NOx in the gas sample. To optimize the performance of this cell, a post sintering treatment has been developed. This treatment yields a consistent and stable composition of the electrode as seen in Figure 31 the hold temperature of the Au containing platinum electrode was varied between $650^{\circ} \mathrm{C}$ and $900^{\circ} \mathrm{C}$. It can be seen that the surface concentration remains quite stable throughout the 2500 -hour exposure at the temperatures tested, even at $900^{\circ} \mathrm{C}$, which is significantly higher than application requirements.

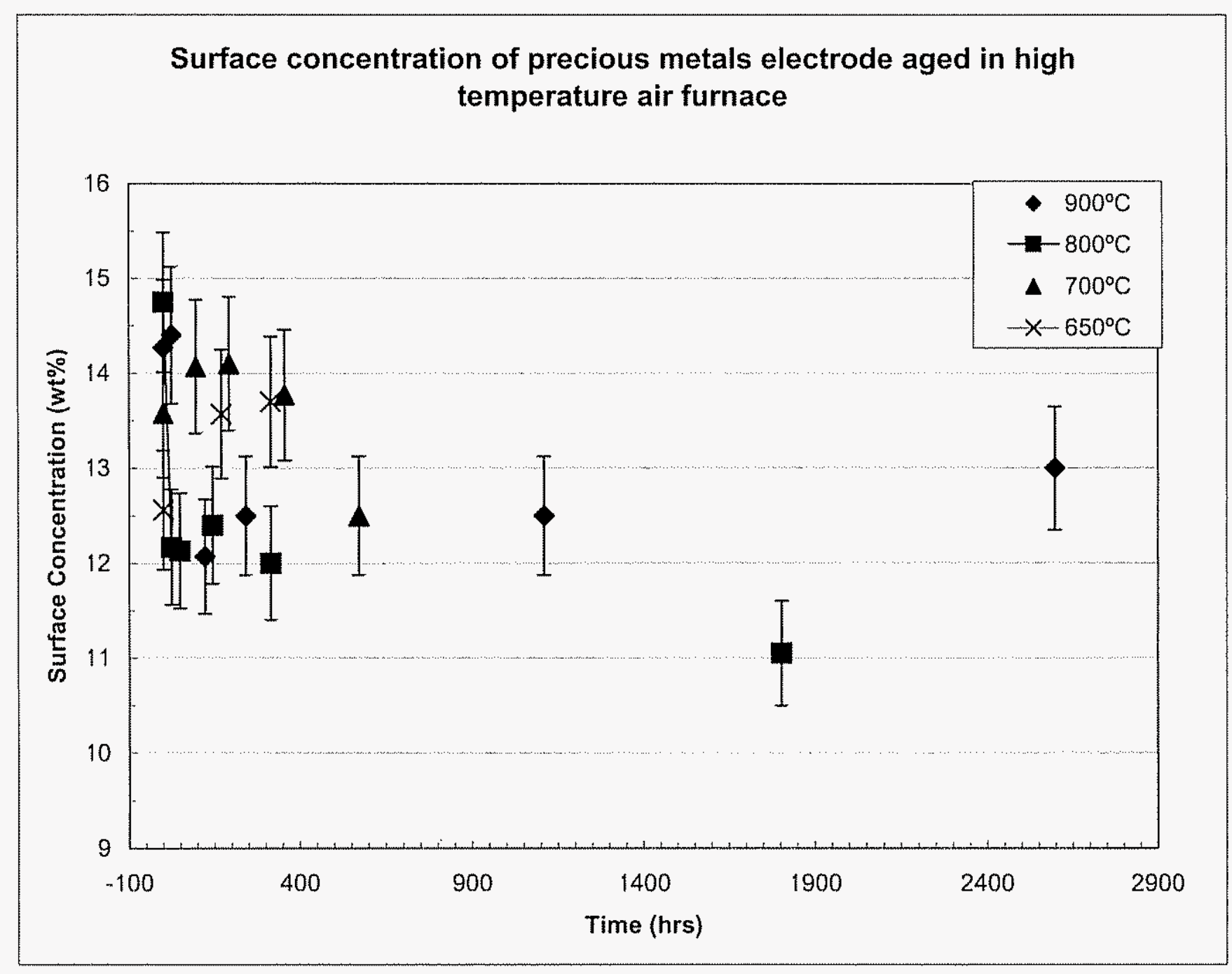

Figure 31: Stability of Precious Metal Alloy Electrode

The ceramic tapes used to form the sense element have between 15 and $18 \%$ binders, plasticizers, and organics that require careful removal during the initial stages of sintering. During the sintering operation, the binders and organics are first removed and then the component undergoes densification during the remainder of the sintering cycle. Figure 32 indicates the difficulty of sintering such a complex structure. Lengthwise delaminations are easily seen on the sense elements pictured. This is a result of excessive stresses during the de-bindering (initial stages of sintering) of the component. A study of the weight loss of the sense element using Therma-Gravimetric Analysis indicated that the organics were evolving at a much lower temperature and higher percentage then originally thought. 
Effective solutions were either to significantly extend the binder removal period by carefully decreasing the rate of temperature rise in the high loss regions, or de-binder in an inert atmosphere such as Argon to avoid combustion processes that cause high stress on the part. Success was achieved through a slow binder removal process in Argon to avoid any ignition of the organics in the removal step.

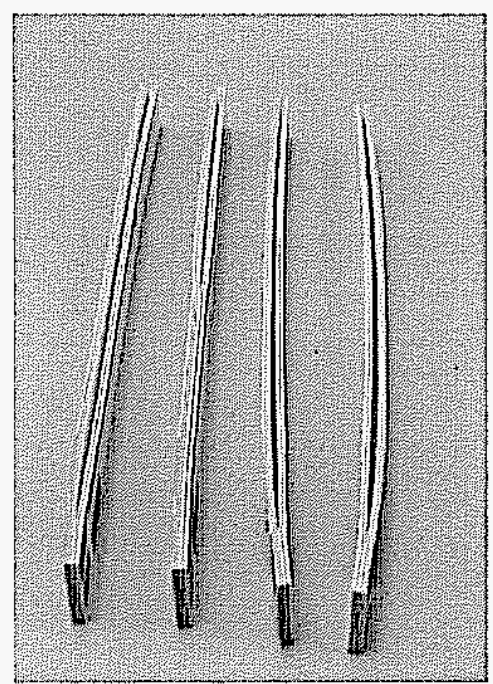

Figure 32: Sense Elements

The use of Argon adds significant cost and complexity to the sintering operation. An alternative solution has been achieved through the use of a constant weight rate loss of the organics in air shown as Figure 33. This involves modifying the binder removal profile so that a constant rate of organics weight loss is achieved. Using this technique eliminates undue stresses on the ceramic during the binder removal phase of sintering. Implementation of this technique has allowed the successful sintering of the complex shape NOx sense elements. The majority of sense elements fabricated are free from defects that would interfere with the performance or structural integrity of the device.

Constant Woight Loss Rate (CWLR) Firing Schedule vs Trial Programmed heating Schedule

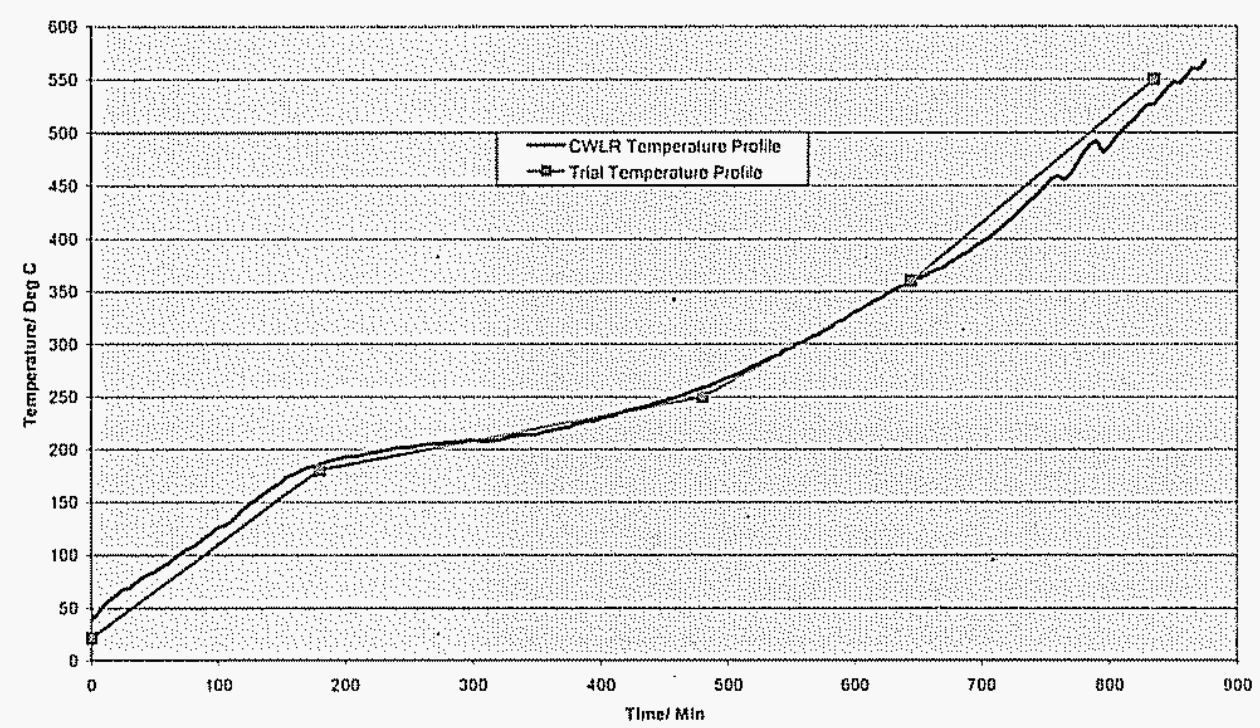

Figure 33: Constant weight rate loss 
There was a need to switch to a new supplier for the green ceramic tapes at a later stage in the project. The original source was discontinuing supply. The move to the new source of tape was successful after several tape lots and trial sense element builds were made. A number of processing parameter adjustments were identified and carried out to enable the successful transition to the new tape source. A substantial quantity of NOx sense elements were fabricated and sintered to ensure the new tape was capable. 


\section{CONCLUSIONS}

Materials development played a key role in shaping the sense element design and structure. Specialized electrodes and processes were developed to obtain the desired performance. Simple test coupons were used to optimize electrode performance and to understand basic electrode behaviors. It is understood that some method of removing oxygen without reducing NOx is a key feature of the design. Small additions of Au to platinum electrodes allows for the separation effect to take place. It is also concluded that all oxygen removal from a sample gas cannot effectively be accomplished by one pump cell/ electrode. Reduction in NOx species occurs when this was attempted. Therefore a two-step approach is warranted. The chosen design structure incorporates 2 cells to achieve near 0 $\mathrm{ppm}$ level oxygen removal. The first pump/separation cell removes the majority of oxygen constituents. The second pump cell removes the remaining oxygen without reducing NOx. The NOx can then be successfully measured using a third cell. A NOx sense element was constructed using similar planar technology to that of Delphi's wide range oxygen sensor. This incorporates a heater to maintain the proper operating temperature of the device. The element incorporates both alumina and zirconia ceramics. Diffusion paths, chambers, and air channels are also features of the device.

In order for the NOx sensor to operate, an electronic controller was developed. This device controls the heater to the operating set point, controls the cells that remove oxygen from the gas sample, and ultimately measures NOx. The chief issue with the controller is working with the incredibly small output signal from the sensor. The output is on the order of NanoAmps to MicroAmps. In an attempt to increase the signal strength, Differential Pulse Voltammetry was investigated, as well as continuous mode operation. After significant study, roadblocks were reached with the DPV approach, so all effort was focused on the continuous mode control. Once the development controller operation was confirmed, a Gen I controller was designed and built. This controller was useful in working with the first fully functional NOx sensors. The sensors were evaluated on static and dynamic gas benches, diesel dynamometers, and vehicles. A list of refinements to both the sensor and controller hardware was compiled and revisions made over time. Eventually, a Gen II controller was created which has many improvements to the operation and control of the sensor.

One key area of development for the NOx sensor was the intercomnection of signal and power to the device. Normally, mechanical connection is the method of choice for exhaust sensors and has proven to be robust. Due to the increased wire count (from 5 to 8 wires) from previous exhaust sensors, a SBCE approach was used to limit the risk. Direct welding of the wires to the substrate pads looked like a promising alternative to mechanical connection, but the process carried higher manufacturing costs and complexity, leaving mechanical connection as the chosen method. NOx sensors with mechanical connection successfully survived $60 \mathrm{hrs}$ of hot vibration and shock testing on an engine dynamometer, which represents about 200,000 miles of vehicle use

NOx sensors were further tested on a vehicle for over 20,000 miles and remained functional throughout that vehicle exposure. Other sensors were evaluated on diesel dynamometers and showed good correlation to reference NOx sensors and analyzers.

Additional refinements to the NOx sensor had been made to improve accuracy of the device. Throughout the development period, many improvements were made to both the NOx sensor and controller. It is concluded that continued testing will highlight additional areas of improvement to make the sensor more accurate and repeatable from part to part, as well as, more durable and lower cost. 


\begin{tabular}{ll} 
List of Acronyms: & \\
\hline NOx & Oxides of Nitrogen \\
SBCE & Set Based Concurrent Engineering \\
CIDI & Compression-Ignition Direct Injection \\
ppm & Part per million \\
CRADA & Cooperative Research and Development Agreement \\
PNNL & Pacific Northwest National Laboratory \\
BoB & Best of Best \\
WoW & Worst of worst \\
S/N & Signal to Noise \\
ECM & Electronic Control Module \\
Au & Gold \\
Ni & Nickel \\
CV & Cyclic Voltammetry \\
$\mathrm{mV}$ & Millivolt \\
$\mathrm{MicroA}$ & MicroAmps \\
$\mathrm{mm}$ & Millimeter \\
$\mu \mathrm{m}$ & Micron
\end{tabular}

